\title{
Modelling Integration of System Dinamics and Game Theory for of Financial Technology Peer to Peer Lending Industry
}

\author{
Deririnda Setyo Anresnani ${ }^{1,{ }^{*}}$, Erwin Widodo ${ }^{1}$ and Bambang Syairuddin ${ }^{1}$ \\ ${ }^{1}$ Department of Industrial Engineering, Sepuluh Nopember Institute of Technology, 60111 Surabaya, \\ Indonesia
}

\begin{abstract}
In Indonesia, internet users from 2013 to 2018 have increased about $52 \%$. This growth indicates that people behaviour change in many aspects of life including in economy. One example is (Fintech P2P Lending). P2P lending is a service that offers online borrowing, lenders can loan to small business or individuals. This is in line with the Indonesia Financial Services Sector Master Plan 2015-2019. Indonesia support the rapid growth of the financial technology ecosystem, but there is need good understanding between related parties such as P2P Lending companies, lenders and borrowers. A system dynamics act as calculators to takes value to fill payoff table in game theory. Integration of system dynamics and game theory can produce the best strategy for Fintech P2P Lending in running its business while considering profit for lenders and borrowers. The best strategy is known by use non-cooperative and cooperative game theory. The result shown the best strategy for each player with noncooperative game is when the company chooses a high level of profit margin, borrower chooses low level of debt time, and lender chooses high level of ROI. In cooperative game, the best strategy is when the company chooses a high level of profit margin, borrower chooses low level of debt time, and lender chooses low level of ROI.
\end{abstract}

\section{Introduction}

Nowadays, the development of information system and technology in Indonesia have been increasing rapidly, internet users from 2013 to 2018 have increased about 52\%. This growth indicates that the level of technology utilizations of Indonesian people is very high. Furthermore, it changes people behaviour in many aspects of life including in economy. One example is emerging of Financial Technology (Fintech). Fintech is a disruptive innovation that introduces practicality, convenience, ease of access, and economical cost. This kind of innovation basically transforms a system or existing market that is less desirable by market rulers to be something that will be demanded and needed by the community [1].

In this study, business processes will be examined towards peer-to-peer landing (P2P Lending). P2P lending is a service that offers online borrowing, lenders can loan to small business or individuals. Initially, the essential trait that described P2P Lending as "elective"

\footnotetext{
${ }^{*}$ Corresponding author: deririnda@gmail.com
} 
was a guarantee to 'return' to casual and direct lending inside a group of put stock in peers. The desire to 'cut out the middle-man' or to generally decrease grating in encouraging access to product and services has been a centre component behind the drive of internet based trade [2].

In Global Partnership for Financial Inclusion [3], digital finance and financial inclusion like P2P Lending have a few advantages to providers of digital finance, users of financial services, government and the economy, for example, expanding access to finance among poor people, poverty reduction, increasing aggregate expenditure for governments and economy growth. This is in line with the Indonesia Financial Services Sector Master Plan 2015-2019 which has three targets that are contributed in supporting the acceleration of national economic growth, maintaining stable financial system as a foundation for sustainable development, and inclusive improving the welfare of the community by opening access to finance [1].

Behind Indonesia's bravery in supporting the rapid growth of the financial technology ecosystem, there is still need for a good understanding between related parties such as P2P Lending companies, investors and borrowers. That way, the development of Fintech P2P Lending industry is able to fulfil the needs of each stakeholder without anyone feeling disadvantaged. However, current condition of Fintech P2P Lending has some challenges to develop. This research will use systems dynamic and game theory approach to make the best strategy that can be applied to develop Fintech industry in Indonesia especially in P2P Lending business. Game theory is used as a multiplayer decision model and system dynamic acts as calculator to fulfil payoff table in game theory. Fintech P2P Lending has a role to get benefit from the provision of platforms, lenders as providers of funds that expect the benefits of investing activities, and borrowers are interested to borrow funds by considering the specified interest rate. The interaction between three players makes it possible to analyse the best logical and rational strategies, so that every player achieves the highest utility. It is hoped that integration of system dynamics and game theory can produce the best strategy for Fintech P2P Lending in running its business while considering profit for lenders and borrowers.

\section{Related Research}

A review of previous research was conducted to determine the position and differences of current research, the research on the topic of Fintech P2P Lending with various methods, and similar methods used in various problems. Oanh Truong [4] describes the evolutionary history of Fintech, identifies the success factors of Fintech and its real-life applications, and demonstrates Fintech's changing innovations in different areas, including online banking and payment processes (individual and group consumers). The evolution of digital technology changes consumer behaviour and traditional business model. Fintech plays a key role in sustained economic growth. Conventional business should be more flexible and adaptation to the development of the era in order to still exist.

Chrismastianto [5] analyze more deeply about the strengths, weaknesses, opportunities, and threats (SWOT) of the implementation of financial technology on the quality of banking services in the digital era through the study of banking literature. The financial technology has a good level of effectiveness to improve the quality of banking services in Indonesia, so that the banking management can implement it to reach all levels of Indonesian society, especially for people living in 3T (Outside, Outermost and Remote).

Can Erman [6] use qualitative study with several different perspectives. Semi-structured interviews, reports of corporate consultants, economic reports of the organization, company website. This research have several purpose that understand the triggers of Fintech's 
development, the role of Open Innovation methods in the field, shows the advantages and disadvantages of the target player and Fintech, and define risk and challenge of Fintech.

Qingyao Wan, Dongyu Chen, Weihua Shi [7] explore the lender's decision making process in online peer-to-peer (P2P) lending using trust theory and valence frameworks to develop integrated decision models. The results showed that initial trust and perceived benefit determined willingness to lend, and that the fear of borrower opportunism did not have a significant impact on this willingness. Initial trust increased willingness to lend both directly and indirectly, increased it by increasing perceived benefit.

Dongyu Chen, Fujun Lai, Zhangxi Lin [8] develops an integrated trust model specifically for the online P2P lending context, to better understand the critical factors that drive lenders' trust. The results show that both trust in borrowers and trust in intermediaries are significant factors influencing lenders' lending intention. However, trust in borrowers is more critical, and not only directly nurtures lenders' lending intention more efficiently than trust in intermediaries, but also carries the impact of trust in intermediaries on lenders' lending intention.

Quanlong Liu, Xinchun Li, Maureen Hassall [9] describe the interactions between the stakeholders in China's coal mining safety inspection system, and analyze the stability of stakeholder interaction and to identify equilibrium solutions. Budianto [10] develops improvement model of tuna fishery system in the coast of Sendang Biru and to determine the best sustainable scenario to be applied by the local government, fish traders, and fisherman in term of profit achieved. The improvement simulation model for better result is held from 2016 to 2025 with 3 changing variable, local ship limit, number of fishing trip, and tuna trading profit margin.

In previous research, Fintech P2P Lending was discussed in qualitative or quantitative terms. Therefore, this research will discuss Fintech P2P Lending in qualitative and quantitative. Qualitative will be presented in dynamic system modelling, then the best strategy determination will be done quantitatively by using game theory method.

\section{The Model}

In this study, system dynamics will be used in combination with the cooperative game theory. The relationships and behaviours of Fintech P2P Lending, lenders, and borrowers are analysed to establish the diffusion system and the mathematic model. It started by identifying the system framework, modelling system, strategic form of the game.

\subsection{System Framework}

The system framework describes the variable of Fintech P2P Lending system into controlled input (decision variable), uncontrolled input (parameter), and desirable output (response). System dynamics simulation is used as the tool to find payoff in the game theory payoff matrix. Then, game theory approach is used as a multiplayer decision model of situations that choose strategy for all of the players. Uncontrolled input is the behaviour of the system which all of player cannot control it, controlled input is the strategy of the players in game, and desirable output is the payoff of each player based on the uncontrolled and controlled input. 


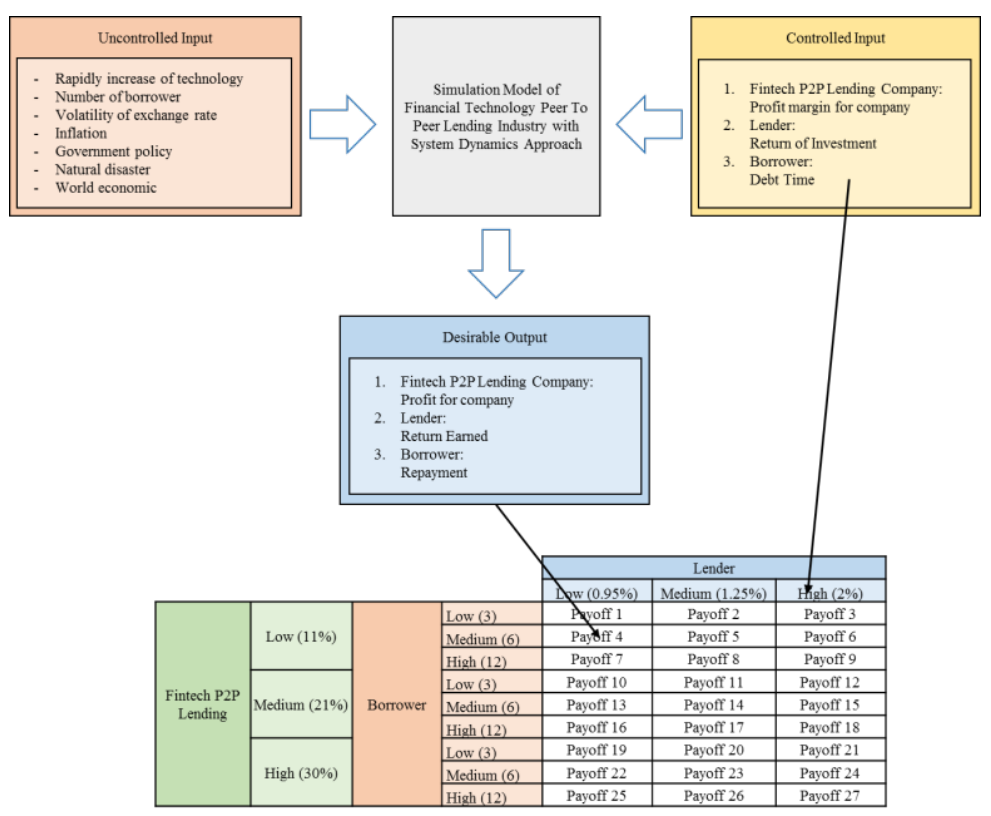

Fig. 1. Research Framework Combination of System Dynamic and Game Theory Approach

\subsection{System Dynamics}

The Fintech P2P Lending system is modelled into three sector, which are; P2P Lending sector, lender sector, and borrower sector. The conceptual model is shown in stock and flow diagram that illustrate the interrelationships between variables involved in observational systems and their relationship.

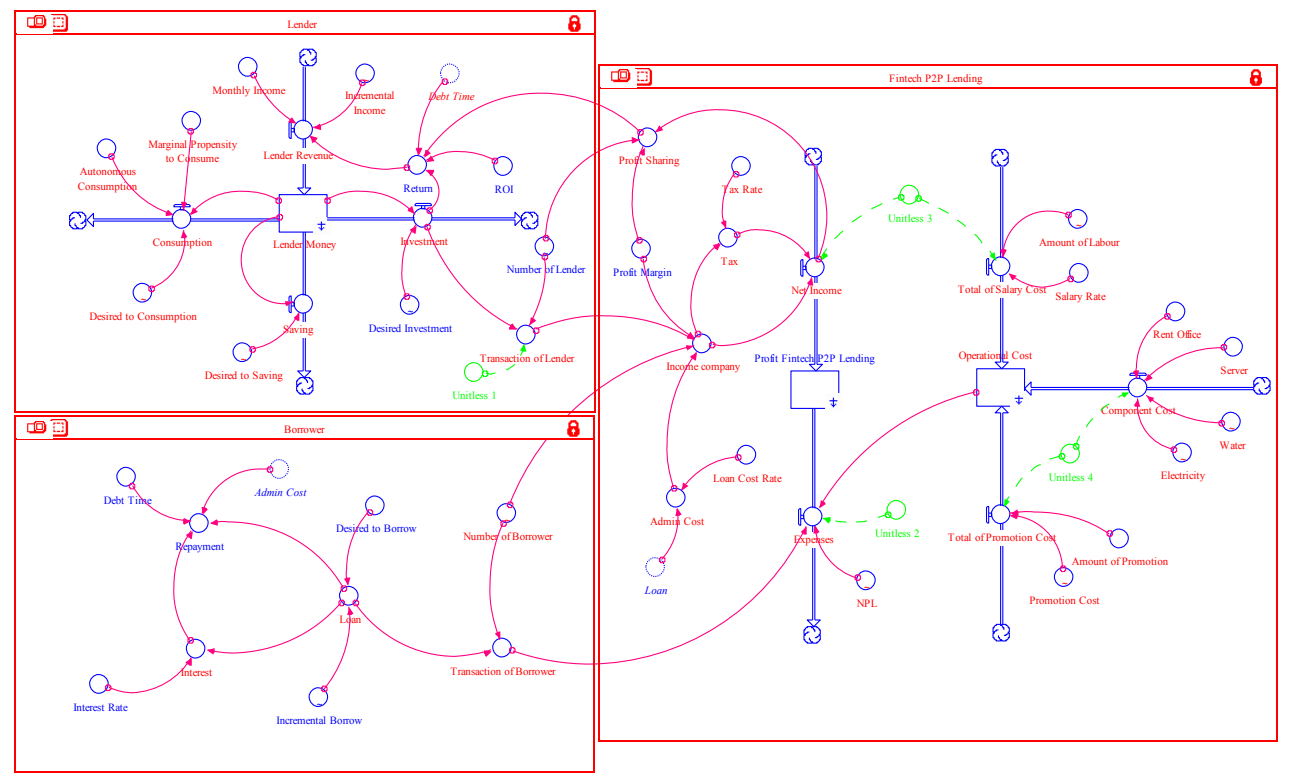

Fig. 2. Stock and Flow Diagram of Fintech P2P Lending System 
Stock and flow diagrams illustrate the interactions between variables according to the structure logic in the modelling software used. The design of stock and flow diagram also consider the purpose of research where the stock and flow diagram can generate influence of policy instruments on observation system. Each variable in the model is executed and will generate the output as a value in the game playoff payoff matrix. In the sub model lender, the expected output to fill payoff in game theory is the amount of return earned after investing. In the sub model borrower, the desired output is the amount of repayment, and in the sub model Fintech P2P Lending is profit for the company.

\subsection{Game Theory Analysis}

Game theory is a mathematical approach to formulate a strategy that involves a decision maker with various interests. The payoff value of each player is determined from the input variables. On this research, the payoff matrix has three players with three strategies. The players involved and their strategies are;

1. Fintech P2P Lending: Profit margin company (low, medium, high)

2. Lender: Return of investment (low, medium, high)

3. Borrower: Debt time (low, medium, high)

For profit margin divided into $11 \%, 21 \%$, and $30 \%$. For ROI gained lenders use $0.95 \%$, $1.25 \%$, and $2 \%$. For borrower can choose debt time 3, 6, or 12 months. This input will generate matrix payoff as below:

Table 1. Payoff Matrix (Normal Form) of Fintech P2P Lending System

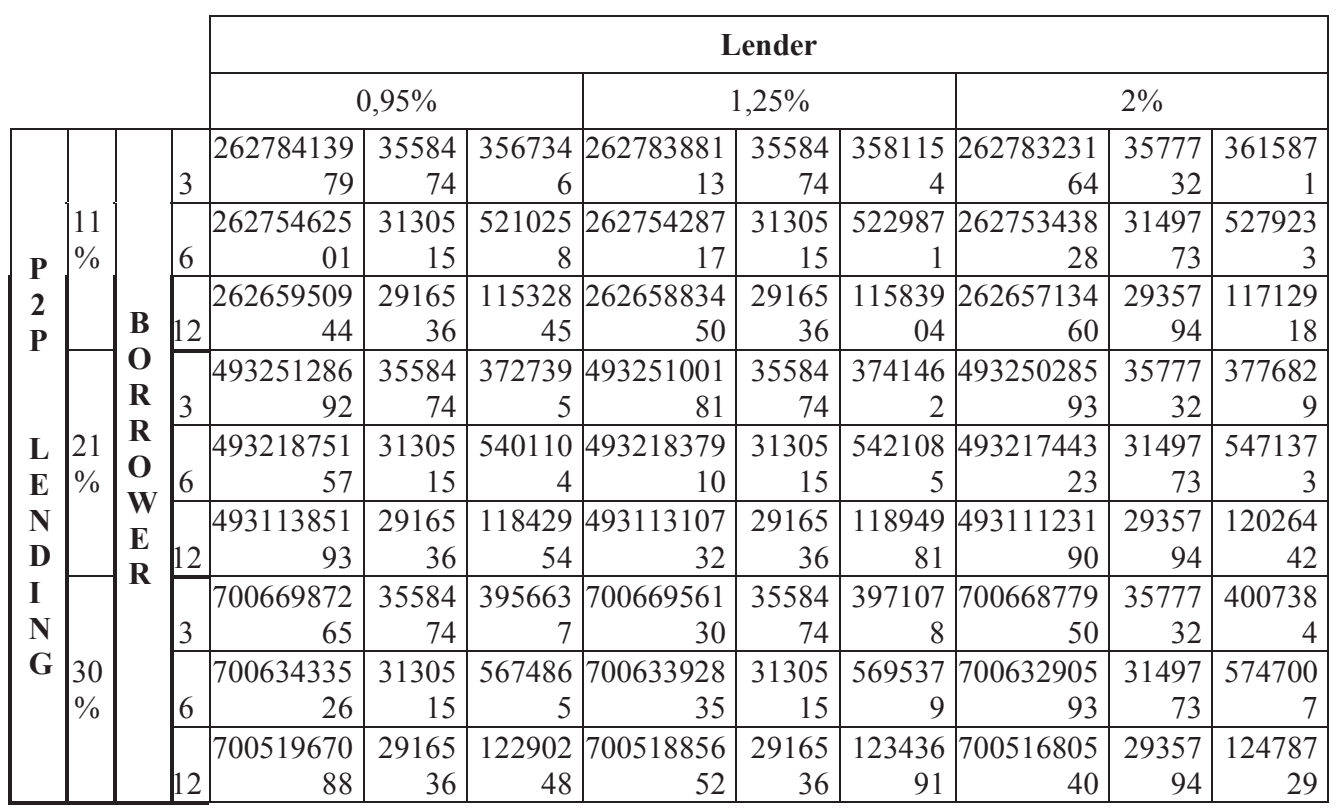

* payoff unit is in rupiah

Based on Gambit running, it is known that the equilibrium for Fintech P2P Lending, lender and borrower. The results show for Fintech P2P Lending can choose a high strategy that is set profit margin of $30 \%$ and borrower choose low strategy with duration of 3 month return period. As for lenders can take the ROI of $2 \%$. However, this result is not the best because this chosen strategy not giving the highest total value from all players. Thus, the cooperative game theory is applied. The first step that must be done to analyze the problem with cooperative game theory is to change the normal form of payoff matrix into the 
coalition form, then the solution of the game is determine using Nash Equilibrium method. In order to find the highest possible payoff, the payoff of each player needs to be sum.

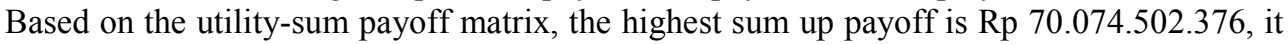
defines that the best strategy is high profit margin for Fintech P2P Lending, low return of investment for lender, and low debt time for borrower.

\section{Conclusion}

The model of Fintech P2P lending system is build using the system dynamics approach. The model is described using the causal loop diagram and then will be using stock-flow diagram. In the simulation, there are three changeable variables used such as profit margin desired by the company, loan repayment time by consumer, and return earned by lenders based on ROI. The numbers obtained in the system dynamic will be the payoff value in game theory to find the best strategy for each player. In game theory, the payoff table of each player will contain the result number from running in the dynamic system model. The best strategy is known by use non-cooperative and cooperative game theory. The result shown the best strategy for each player with non-cooperative game is when the company chooses a high level of profit margin, borrower chooses low level of debt time, and lender chooses high level of ROI. In cooperative game, the best strategy is when the company chooses a high level of profit margin, borrower chooses low level of debt time, and lender chooses low level of ROI.

For further research, model of Fintech P2P Lending system need to develop so it can be widely seen and detailed. It is also considering more complex strategies and some player that are directly related.

\section{References}

1. M. D. Hadad, Jakarta (2017)

2. Mateescu, Peer-to-Peer Lending, Data \& Society (2015)

3. Global Partnership for Financial Inclusion, "G20 High-level principles for digital financial inclusion.," 9 April 2010. [Online]. Available: https://www.gpfi.org/sites/default/files/G20\%20High\%20Level\%. [Diakses 2018 April 2018].

4. O. Truong, Centria University of Applied Science (2016)

5. A. W. Chrismastianto, ISSN, Tangerang (2017)

6. Erman, ResearchGate (2017)

7. C. W. S. Qingyao Wan, 1 117-130 (2016)

8. F. L. Z. L. Dongyu Chen, Springer, 15 239-254 (2014)

9. X. L. M. H. Quanlong Liu, Safety Science, 80 13-22 (2015)

10. Budianto, Surabaya (2017) 